\title{
AS DIMENSÕES DOS MODELOS MENTAIS DOS EMPREENDEDORES E SEUS IMPACTOS SOBRE O DESEMPENHO ORGANIZACIONAL
}

\author{
Deonir de Toni \\ deonirdt@terra.com.br \\ Universidade de Caxias do Sul - Caxias do Sul, RS / Brasil \\ Gustavo Mioranza \\ gutomio@hotmail.com \\ Universidade de Caxias do Sul - Caxias do Sul, RS / Brasil \\ Gabriel Sperandio Milan \\ gabmilan@terra.com.br \\ Universidade de Caxias do Sul - Caxias do Sul, RS / Brasil \\ Fabiano Larentis \\ flarenti@ucs.br \\ Universidade de Caxias do Sul - Caxias do Sul, RS / Brasil
}

http://dx.doi.org/10.1590/1413-2311.0312013.43234

Recebido em 18/07/2013

Aprovado em 16/06/2014

Disponibilizado em 01/12/2014

Avaliado pelo sistema double blind review

Revista Eletrônica de Administração

Editor: Luís Felipe Nascimento

ISSN 1413-2311 (versão on-line)

Editada pela Escola de Administração da Universidade Federal do Rio Grande do Sul.

Periodicidade: Quadrimestral

Sistema requerido: Adobe Acrobat Reader.

\section{RESUMO}

Este trabalho objetiva identificar as dimensões e variáveis básicas dos modelos mentais dos empreendedores, bem como os seus impactos sobre o desempenho de suas empresas. Para isso, foi realizada uma pesquisa qualitativa com seis empreendedores, e uma pesquisa quantitativa com 113 empresas do setor metalomecânico na Serra Gaúcha. Dentre as contribuições deste trabalho, destaca-se, primeiramente a proposição de um modelo teórico no qual se identificam sete dimensões dos modelos mentais dos empreendedores relacionadas ao desempenho organizacional. Uma segunda contribuição é a proposição de uma escala para a mensuração dos modelos mentais dos dirigentes das empresas. Os resultados da pesquisa confirmam que a escala proposta se ajustou bem às dimensões identificadas na revisão da literatura e que dentre as sete dimensões apresentadas, as que estão relacionadas ao conhecimento, ao relacionamento, à missão e à estratégia, à criatividade e à vocação apresentaram um impacto significativo sobre o desempenho das organizações analisadas. Verificou-se que $27,5 \%$ do poder explicativo do desempenho organizacional pode estar associado às dimensões formadoras dos modelos mentais dos empreendedores.

Palavras-chave: Modelos Mentais; Dimensões dos Modelos mentais; Desempenho Organizacional. 
As dimensões dos modelos mentais dos empreendedores e seus impactos sobre o desempenho organizacional

\title{
DIMENSIONS OF MENTAL MODELS OF ENTREPRENEURS AND THEIR IMPACT ON ORGANIZATIONAL PERFORMANCE
}

\begin{abstract}
This study aims to identify the dimensions and basic variables of entrepreuners' mental models and their impacts on performance of their companies. For this, we conducted a qualitative study with six entrepreneurs and a quantitative survey with 113 companies in the metal-mechanic sector, from Serra Gaucha, Brazil. Among the contributions of this work, first we propose a theoretical model that identifies seven dimensions of entrepreneurs' mental models related to organizational performance. A second contribution is the proposition of a scale to measure the mental models of business leaders. The survey results confirm that the proposed scale fits well to the dimensions identified in the literature review. On the other hand, from among the seven dimensions presented, those related to knowledge, relationships, mission and strategy, creativity and vocation had a significant impact on performance of organizations analyzed. It was found that $27.5 \%$ of the organizational performance explanatory power can be associated to entrepreneurs' mental models forming dimensions.
\end{abstract}

Keywords: Mental Models; Mental Models Dimensions; Organizational Performance.

\section{INTRODUÇÃO}

O desempenho organizacional pode ser configurado por diversos fatores (ou dimensões), sejam eles externos, em uma perspectiva "de fora para dentro", e/ou internos, em uma perspectiva "de dentro para fora". A abordagem de "fora para dentro", defendida por Porter (1986), está relacionada à análise do mercado, configurada por meio das cinco forças competitivas sobre o negócio, a saber: o poder de negociação dos compradores (clientes e/ou consumidores), poder de negociação dos fornecedores, e rivalidade entre os competidores (concorrência), ameaça de produtos e/ou serviços substitutos e ameaça de novos entrantes.

A abordagem de "dentro para fora", por sua vez, tem como principais defensores Hamel e Prahalad (1995), os quais afirmam que o desempenho das organizações é influenciado sobremaneira pela combinação inteligente de competências e de recursos intangíveis. Logo, as competências essenciais (core competences) são recursos intangíveis da organização, os quais são difíceis de imitar e podem agregar valor tanto aos produtos e/ou serviços, quanto ao atendimento às demandas dos clientes. Portanto, é a combinação equilibrada dos elementos externos e internos que conduzem as empresas ao sucesso.

Consoante isso, esta pesquisa teve como objetivo a identificação das dimensões e das variáveis básicas dos modelos mentais dos empreendedores e/ou principais dirigentes de empresas e a verificação de seus impactos sobre o desempenho organizacional. Por 
Deonir de Toni, Gustavo Mioranza, Gabriel Sperandio Milan \& Fabiano Larentis

conseguinte, foram considerados os conhecimentos, as habilidades emocionais, a característica de mente linear, a possibilidade de construção de relacionamentos, a definição da missão e da estratégia empresarial, a criatividade e a vocação para empreender.

Dentre as contribuições da pesquisa, destaca-se a proposição de um modelo teórico e de uma escala para a mensuração dos modelos mentais dos empreendedores. Além disso, o estudo identifica que as dimensões relacionadas ao conhecimento, ao relacionamento, à missão e à estratégia, à criatividade e à vocação apresentaram um impacto significativo sobre o desempenho das organizações analisadas. E isto gera alguns elementos que auxiliam a uma melhor compreensão do porquê algumas organizações obtêm um desempenho superior.

Em relação à estrutura do trabalho, inicialmente, defini-se modelos mentais, abordando as dimensões formadoras dos modelos mentais dos empreendedores e a sua relação com o desempenho organizacional, culminando com a apresentação do modelo teórico e das respectivas hipóteses de pesquisa. Na sequência, são apresentados o método de pesquisa e a análise dos resultados. E, por fim, são tecidas as considerações finais.

\section{MODELOS MENTAIS}

Um modelo mental é, antes de tudo, uma representação dinâmica, e constitui uma maneira específica pela qual o indivíduo percebe, codifica, retém e acessa informações (GARDNER, 2005). Os modelos mentais podem ser descritos como uma visão ampla do mundo, adquirida por meio de experiências passadas, são pressupostos, generalizações ou mesmo imagens arraigadas que influenciam a forma de ver o mundo e agir. São vieses e suposições que as pessoas utilizam para tomar as decisões que direcionam os seus comportamentos (ZALTMAN, 1997; MACHADO-DA-SILVA; FONSECA; FERNANDES, 2000). Os modelos mentais afetam o que se faz, porque afetam como se interpreta o que se vê e o que se acumula em termos de experiência (LIM; KLEIN, 2006).

Os modelos mentais, por serem dinâmicos, estão em permanente estado de construção, constantemente sendo ajustados, refinados e recriados na dinâmica do ambiente, pois possuem um papel ativo no momento que afetam a experiência dos indivíduos, além de um papel passivo, sendo também afetados pela própria experiência em si (CHERMACK, 2003). Inclusive, Gardner (2005, p. 33) afirma que “o conteúdo da mente é, por sua natureza, uma categoria aberta, infinitamente expansível". Para este autor, embora alterar os modelos mentais não seja fácil, mudanças podem ser efetuadas, pois há tantas representações mentais, 
As dimensões dos modelos mentais dos empreendedores e seus impactos sobre o desempenho organizacional

que podem ser combinadas de tantas maneiras diferentes, que as possibilidades de construção de novos modelos são ilimitadas. Neste processo de construção, os modelos mentais se amoldam às interpretações e às respostas ao ambiente (CHAPMAN; FERFOLJA, 2001), sendo que sua mudança requer aprendizagem (JOHNSON-LAIRD, 1983).

Assim sendo, a partir dos estímulos externos, das representações coletivas (culturais) do objeto, bem como das suas próprias representações mentais, o indivíduo forma holisticamente sua representação acerca de um objeto e que, consequentemente, irão influenciar suas ações.

\subsection{As Dimensões dos Modelos Mentais dos Empreendedores e o Desempenho Organizacional}

De acordo com Gartner (2001), as pesquisas sobre empreendedorismo e o perfil dos gestores se caracterizam por serem multidisciplinares, pois requerem o entendimento da atividade de criação em diferentes níveis: individual, em equipe, organizacional e na comunidade. Seguindo a concepção da multidimensionalidade humana (SCHULER, 2005), foram retidas, da revisão de literatura realizada, algumas características da mentalidade empreendedora para criar, de forma exploratória, uma suposição da forma que teria a rede de modelos mentais que impulsionaria o comportamento empreendedor de sucesso, cujos elementos se situam nas seguintes dimensões: (i) conhecimentos de ordem técnica e material; (ii) habilidades emocionais e carismáticas; (iii) a forma de utilização da mente e do raciocínio linear; (iv) habilidades de relacionamento; (v) habilidades estratégicas e visionárias; (vi) criatividade; e (vii) vocação para empreender.

Em uma primeira dimensão, foram encontradas referências a informações ou conhecimentos que o empreendedor deve ter sobre o seu negócio para poder conduzi-lo ao sucesso (LE BOTERF, 2003). Não somente são importantes os conhecimentos técnicos que ele já dispõe sobre o seu negócio, quanto é necessária uma predisposição permanente em adquirir novos conhecimentos, em um mercado ativo e em constante transformação (GOUVEIA; GRISCI, 2006).

Fleury e Fleury (2006) falam de uma competência de negócio, ligada à compreensão do negócio de uma maneira ampla, incluindo a identificação de oportunidades e de ameaças, as necessidades ou exigências do mercado, ao lado da competência técnica, que compreende o conhecimento técnico relativo à sua área de atuação (conhecimento do produto/serviço, 
Deonir de Toni, Gustavo Mioranza, Gabriel Sperandio Milan \& Fabiano Larentis

processo fabril/operações, etc.). Dessa forma, pode-se pressupor a seguinte hipótese de pesquisa:

H1: O conhecimento do empreendedor sobre os aspectos técnicos, aspectos do ambiente de negócio, suas experiências anteriores e sua predisposição para aprender tem um impacto direto e positivo no desempenho organizacional.

A segunda dimensão a ser estudada é a das habilidades emocionais, consideradas importantes para o desempenho nos negócios (SCHULER, 2005). A dimensão emocional humana se manifesta por meio dos hábitos, dos usos, dos costumes e das crenças relacionados à autoestima. Diz respeito à fluência para lidar com as emoções (raiva, medo, tensão, apetite e satisfação, o prazer, a inveja, o ciúme, a alegria, a tristeza); às necessidades de segurança e integridade do corpo físico e da vida, de abrigo e proteção de todos os tipos, à forma de aceitar ou evitar riscos; às características de valor, coragem e constância no mundo como lugar de luta e objeto de conquista.

$\mathrm{Na}$ literatura, há várias menções à importância das emoções para o sucesso dos negócios. A existência de ambição, de independência, autoconfiança e autoconsciência são consideradas características e comportamentos próprios dos empreendedores (GOUVEIA; GRISCI, 2006). Carland, Carland e Hoy (1992), Fernandes et al. (2007), Ferreira, Ramos e Gimenez (2007) e Stewart e Roth (2007) se referem à propensão ao risco, como formadora do caráter empreendedor típico, ou seja, da tendência e desejo do indivíduo em aceitar um maior nível de incerteza na motivação para empreender. Veit e Gonçalves Filho (2007) vão além, defendendo que o empreendedor somente se sente estimulado em situações que tragam certo desafio de superação das suas próprias capacidades, sendo que essas situações sempre exigem fluência em assumir riscos. Assim, uma segunda hipótese pode ser apresentada:

H2: As habilidades emocionais do empreendedor nos aspectos da autoestima, a autoconfiança e aceitação ao risco tem um impacto direto e positivo no desempenho organizacional.

Uma terceira dimensão a ser examinada é a utilização da mente e do raciocínio linear do empreendedor para administrar um negócio. A dimensão mental se constitui de hábitos, usos, costumes e crenças relacionados ao uso da inteligência linear dos indivíduos e da sua inteligência coletiva; às questões de organização social; aos processos de planejamento diário, de efeito mais imediato, onde os fluxos são racionais, lógicos, calculáveis, previsíveis; à tomada de decisão, tanto individual quanto coletiva; à hierarquia; ao exercício de poder e de liderança.

REAd | Porto Alegre - Edição 79 - N 3 - setembro/dezembro 2014 - p. 713-739 
As dimensões dos modelos mentais dos empreendedores e seus impactos sobre o desempenho organizacional

De acordo com Fleury e Fleury (2006) e Le Boterf (2003), para se ter competência não basta saber, é preciso saber colocar em prática os conhecimentos adquiridos, pois a competência se realiza plenamente na ação, inserida em seu contexto. A construção dos conhecimentos, dos desejos e das motivações somente acontece em decorrência da capacidade de formular planos lógicos e inteligentes, da capacidade de mobilizar recursos e lidar com situações difíceis (LE BOTERF, 2003). Consoante isso, emerge a seguinte hipótese:

H3: A utilização da mente linear do empreendedor a partir da organização, da liderança e do planejamento tem um impacto direto e positivo no desempenho organizacional.

É ainda considerada relevante para os empreendedores a orientação para o relacionamento. A habilidade para criar, sustentar e preservar relacionamentos saudáveis e rentáveis, para todos os envolvidos, implica em hábitos, usos, costumes e crenças relacionados ao reconhecimento, ao respeito e à valorização dos outros; à aceitação das diferenças individuais; ao saber dar e receber; à solidariedade e ao compartilhamento; ao equilíbrio entre justiça e misericórdia, nas relações.

Para Vasconcellos (2007), a manutenção de relacionamentos ou a interação entre as pessoas cria oportunidades. A afeição desenvolvida entre as pessoas gera motivação e com o passar do tempo acumula-se experiência, que leva à troca de informações. A combinação destes aspectos é que caracteriza um laço de confiança do empreendedor em relação aos stakeholders da empresa, o que é essencial. Cordeiro e Mello (2006) também defendem que o empreendedorismo deva ir além do paradigma funcionalista, que privilegia uma visão economicista e individualista, sendo o sujeito-empreendedor um agente político de um fenômeno genericamente coletivo, pautado pela ajuda mútua, pela solidariedade e pela ação cooperativa. Propõe-se, então, a quarta hipótese de pesquisa:

H4: A manutenção de relacionamentos dos empreendedores pautado no reconhecimento, no respeito, na valorização entre os stakeholders tem um impacto direto e positivo no desempenho organizacional.

A dimensão seguinte reúne a missão e a estratégia empresarial. Carland, Carland e Hoy (1992), Fernandes et al. (2007), Ferreira, Ramos e Gimenez (2007) e Stewart e Roth (2007) salientam a importância, para a mentalidade empreendedora e ligada à gestão de um negócio, de uma postura estratégica, com visão de futuro, gerada por pensamento sistêmico e intuitivo. Veit e Gonçalves Filho (2007) trazem a ideia de que a mente empreendedora alia ao pensamento analítico e sintético formais, a competência estratégica. 
Deonir de Toni, Gustavo Mioranza, Gabriel Sperandio Milan \& Fabiano Larentis

A Teoria de Orientação para Mercado (KOHLI; JAWORSKI, 1990, NARVER; SLATER, 1990, MÜLLER, 2005) defende que os empreendedores com uma forma de gestão do negócio direcionada a entender e atender os clientes são mais propensos a obterem melhores desempenhos organizacionais (KOTLER; KELLER, 2012; LEVITT, 1990). Dessa forma, os empreendedores que costumam visitar clientes de outras regiões e até de outros países e que participam sistematicamente de feiras e viagens internacionais de negócio apresentam um nível mental mais aberto às inovações e a entender as transformações do mercado. Sendo assim, pode ser estabelecida a seguinte hipótese:

H5: A utilização da missão e das estratégias pelos empreendedores, voltadas ao mercado, tem um impacto direto e positivo no desempenho organizacional.

A criatividade e a tendência à inovação também são comportamentos importantes para o empreendedor. A criatividade faz parte das características e comportamentos que são próprios dos empreendedores (GOUVEIA; GRISCI, 2006). A capacidade de ter iniciativas, indo além das atividades prescritas, sendo capaz de compreender e de dominar novas situações no trabalho, levam à percepção e ao aproveitamento das oportunidades de inovação (FLEURY; FLEURY, 2006).

Cabe ao empreendedor promover uma espécie de "destruição criativa", um processo que traz na inovação uma evolução dinâmica da economia a partir da capacidade de realizar novas combinações. E estas novas combinações podem advir da criação de novos produtos e/ou serviços, de novos modos de produção, de novos mercados, de uma nova fonte de oferta de matéria-prima ou, ainda, de uma nova forma de organização de qualquer indústria (SCHUMPETER, 1982).

Carland, Carland e Hoy (1992), Fernandes et al. (2007), Ferreira, Ramos e Gimenez (2007) e Stewart e Roth (2007) apontam, como característica do empreendedor ou gestor de sucesso, a propensão à inovação e a habilidade de promover novos arranjos que gerem valor econômico com a utilização de recursos existentes. Veit e Gonçalves Filho (2007), por sua vez, valorizam a capacidade de inovação, enquanto Lumpkin e Dess (1996) destacam a postura proativa de inovatividade e de aceitação ao risco.

Ser um empreendedor ou dirigente empresarial criativo é, então, saber integrar ou combinar: saber selecionar os recursos e organizá-los e empregá-los para resolver um problema, como um sistema, em que o todo está integrado nas suas partes é uma das habilidades que acompanha a bom desempenho na solução de problemas. É saber escolher a estratégia adequada para o contexto apresentado. É também saber transpor, adaptando os 
As dimensões dos modelos mentais dos empreendedores e seus impactos sobre o desempenho organizacional

conhecimentos e as habilidades existentes aos diferentes contextos apresentados (SCHULER, 2005). Apresenta-se, assim, mais uma hipótese de pesquisa:

H6: A capacidade criativa e a disposição à inovação do empreendedor tem um impacto direto e positivo no desempenho organizacional.

Finalmente, a vocação para empreender e para o tipo específico de negócio ao qual se dedica constitui mais uma variável importante a ser estudada. O empreendedor de sucesso é aquele que sente forte necessidade de realização; que é orientado, em sua ação, por valores pessoais; que é orientado para o crescimento e evolução constantes (GOUVEIA; GRISCI, 2006). Stewart e Roth (2007) atribuem ao empreendedor competente um forte senso de propósito, ambição, vontade de trabalhar, definida e inabalável.

Tomando-se como premissa de que o ideal do ego se estabelece sobre as bases de identificação com adultos proeminentes, acredita-se que o grupo familiar seria motivo para que os valores nele presentes se constituíssem em base para a escolha do tipo de trabalho futuro. Em síntese, a atuação familiar parece favorecer o desenvolvimento da vocação empreendedora em seus membros (BOHNENBERGER; SCHMIDT; FREITAS, 2007; PAULINO; ROSSI, 2003). Em decorrência disso, surge a seguinte hipótese de pesquisa:

H7: A vocação do empreendedor manifestada em sua necessidade de realização e disposição para o trabalho tem um impacto direto e positivo no desempenho organizacional.

O desempenho organizacional pode ser medido de diferentes perspectivas. Enquanto para alguns empreendedores o sucesso do negócio está no desempenho financeiro outros pode estar na realização pessoal que o negócio em si proporciona. De qualquer forma, buscou-se, por meio deste trabalho, a mensuração do desempenho sob uma perspectiva econômica. Para tanto, consideramos válida a adoção do número de clientes ativos, do volume de negócios (faturamento), do market share (participação de mercado), do lucro e da rentabilidade e do valor de mercado da empresa ou de suas ações (PFEFFER, 2005) como variáveis adequadas para uma futura investida empírica no sentido de avaliar a influência da mentalidade do empreendedor sobre o desempenho organizacional.

Com o propósito de representar as relações entre os construtos contemplados na pesquisa, elaborou-se o modelo teórico apresentado na Figura 1, com as respectivas hipóteses de pesquisa formuladas. 
Deonir de Toni, Gustavo Mioranza, Gabriel Sperandio Milan \& Fabiano Larentis

Figura 1 - Modelo teórico proposto e hipóteses de pesquisa

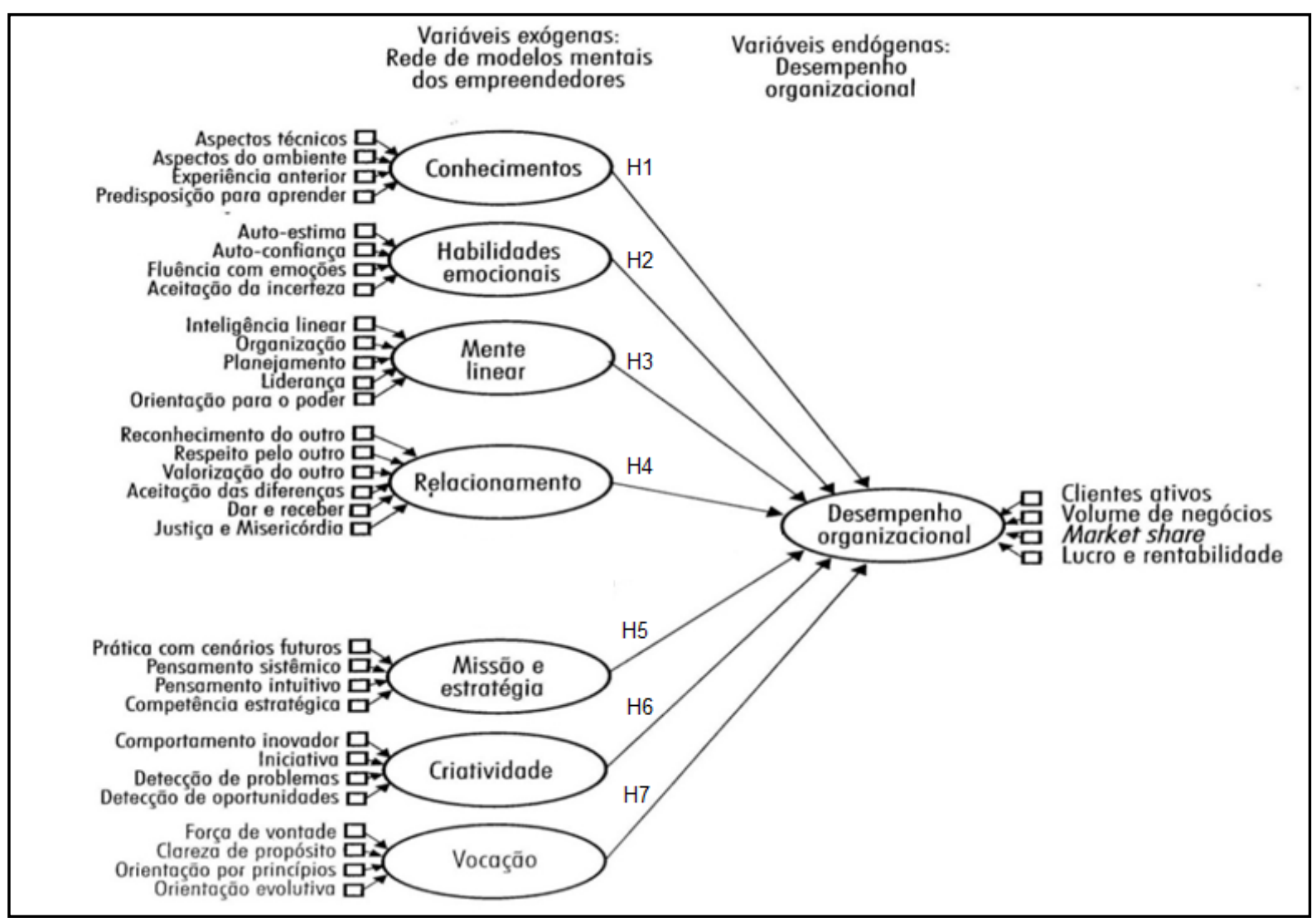

Fonte: Elaborada pelos autores.

É importante destacar que o modelo considera os construtos envolvidos no estudo, de natureza independente, ou endógena (conhecimentos, habilidades emocionais, mente linear, relacionamento, missão e estratégia, criatividade e vocação), e de natureza dependente, ou exógena (desempenho organizacional). Em relação a cada construto da Figura 1, são apresentadas as suas especificidades ou variáveis que podem compor estes constructos. Assim, para cada uma das sete relações hipotetizadas, o desempenho organizacional é influenciado de forma positiva e direta pelas dimensões que compõem os modelos mentais dos empreendedores.

\section{MÉTODO DE PESQUISA}

A pesquisa foi realizada em duas fases. A primeira fase de cunho qualitativoexploratório e, a segunda, de cunho quantitativo-descritivo (MALHOTRA, 2011).Na pesquisa exploratória, buscou-se subsídios para a construção da escala para as identificações de modelos mentais de empreendedores. Já na pesquisa descritiva, buscou identificar a REAd | Porto Alegre - Edição 79 - N 3 - setembro/dezembro 2014 - p. 713-739 
As dimensões dos modelos mentais dos empreendedores e seus impactos sobre o desempenho organizacional

unidimensionalidade de cada construto (dimensões de análise) e o quanto cada um deles pode explicar o desempenho das organizações.

A pesquisa foi realizada na cidade de Caxias do Sul, no Estado do Rio Grande do Sul (RS), pois se trata do segundo maior pólo metalomecânico no país (TONET; TONET, 2010). O setor metalomecânico compreende 2.200 empresas e gera cerca de 50.000 postos de trabalho na cidade. O total de faturamento das empresas é de R \$ 5,9 bilhões. As empresas do setor, basicamente, podem ser classificadas em quatro categorias de atuação: automotiva leve, média e pesada, eletroeletrônica, metalomecânico e micro e pequenas empresas.

\subsection{Pesquisa Qualitativa-Exploratória}

Visando compreender melhor o segmento e auxiliar na construção de um instrumento de coleta de dados, foi realizado um estudo exploratório por meio de entrevistas com seis empreendedores do setor metalomecânico da região de Caxias do Sul (RS), sendo que o critério utilizado foi o de empresas que tivessem mais de 20 anos de mercado e cujo desempenho fosse diferente entre si.

O processo de coleta de dados foi implementado por meio de entrevistas individuais em profundidade, adotando-se uma abordagem semiestruturada, mediante a aplicação de um roteiro básico de questões (RIBEIRO; MILAN, 2004; FLICK, 2004), desenvolvido a partir da literatura (LE BOTERF, 2003; FLEURY; FLEURY, 2006; DE TONI; MILAN, 2008; MILAN et al., 2009), com as seguintes categorias de análise: modelos mentais (aspecto geral), elemento cognitivo, elemento emocional, elemento simbólico, elemento funcional, conhecimentos técnicos e do negócio, habilidades emocionais, predisposição para aprender, liderança, família e cultura, relacionamentos, missão e estratégia, criatividade e inovação, vocação e desempenho. As entrevistas foram realizadas em sessões únicas e tiveram uma duração de aproximadamente uma hora e meia. As entrevistas ocorreram em janeiro e fevereiro de 2012 nas instalações das empresas dos pesquisados.

As respostas dos entrevistados foram gravadas em meio magnético e posteriormente transcritas para facilitar sua análise e interpretação (RIBEIRO; MILAN, 2004; WOLCOTT, 1994). O processo de análise de conteúdo seguiu os pressupostos defendidos por Bardin (2004), além dos cuidados prescritos por Wolcott (1994) e Flick (2004) no que diz respeito ao tratamento e à análise e interpretação de dados provenientes de pesquisas qualitativas, valendo-se, inicialmente, dos conteúdos provenientes das entrevistas, e devidamente 
Deonir de Toni, Gustavo Mioranza, Gabriel Sperandio Milan \& Fabiano Larentis

transcritos, e categorizados em dimensões de análise, ou temas, conforme apresentado na revisão da literatura e sumarizados na Figura 1.

A partir da resposta destas entrevistas foi possível identificar que o discurso dos entrevistados no que diz respeito ao desempenho de suas organizações estavam alinhadas às dimensões investigadas. Portanto, esta etapa da pesquisa foi importante e contribui primeiro para verificar a validade de conteúdo (HAIR Jr. et al., 2009) das dimensões de análise pois nesta etapa os empreendedores analisaram o quanto estas dimensões refletiam no desempenho das suas organizações; e segundo, serviu de suporte para a construção do instrumento de coleta de dados desenvolvido na pesquisa quantitativa-descritiva e apresentada a seguir.

\subsection{Pesquisa Quantitativa-Descritiva}

A pesquisa quantitativa-descritiva foi realizada de março a abril de 2012 e teve por objetivo testar um instrumento de coleta de dados desenvolvido a partir da revisão da literatura e da pesquisa qualitativa-exploratória. Assim sendo, foram aplicados 347 questionários, sendo que se obteve um retorno de 117 casos válidos, ou seja, uma taxa de retorno de 33\%. Cabe ressaltar que a amostragem foi por conveniência. Para a coleta dos dados, primeiramente, foi feito um contato por telefone para identificar o principal empreendedor do negócio e a sua disponibilidade de responder ao questionário. Em um segundo momento, os questionários foram encaminhados por e-mail. O tempo médio de recebimento dos questionários foi de sete dias, sendo que alguns casos foram necessários novos contatos para que os respondentes encaminhassem o questionário respondido.

\subsubsection{Instrumento de Coleta e Análise de Dados}

A partir da revisão da literatura em que identificou-se sete dimensões dos modelos mentais dos empreendedores e do estudo qualitativo-exploratório com seis empreendedores com diferentes níveis de desempenho organizacional, foi possível propor um instrumento de pesquisa com vista a identificar parte dos modelos mentais dos empreendedores que impactam no desempenho de suas organizações. Dessa forma, o Quadro 1 apresenta as questões que são propostas para a mensuração de cada uma das dimensões identificadas na literatura, bem como os principais autores que foram pesquisados. 
As dimensões dos modelos mentais dos empreendedores e seus impactos sobre o desempenho organizacional

Quadro 1 - Instrumento de coleta de dados

\begin{tabular}{|c|c|c|}
\hline \multirow{2}{*}{$\mathbf{N}^{\mathbf{o}}$} & Variáveis & \multirow{2}{*}{ Adaptado de } \\
\hline & Conhecimentos & \\
\hline 1 & $\begin{array}{l}\text { O meu conhecimento dos aspectos técnicos do produto é um fator crítico para o } \\
\text { desempenho da minha empresa. }\end{array}$ & \multirow{6}{*}{$\begin{array}{c}\text { De Toni, } \\
\text { Milan e } \\
\text { Schuler } \\
\text { (2009) e Le } \\
\text { Boterf (2003) }\end{array}$} \\
\hline 2 & $\begin{array}{l}\text { O meu conhecimento dos processos produtivos é um fator crítico para o desempenho da } \\
\text { minha empresa. }\end{array}$ & \\
\hline 3 & $\begin{array}{l}\text { O meu conhecimento do ambiente competitivo (mercado de atuação) é um fator crítico } \\
\text { para o desempenho da minha empresa. }\end{array}$ & \\
\hline 4 & Minha experiência anterior foi um fator importante para o desempenho da minha empresa. & \\
\hline 5 & $\begin{array}{l}\text { Busco com frequência novos conhecimentos para melhorar o desempenho da minha } \\
\text { empresa. }\end{array}$ & \\
\hline \multirow[t]{2}{*}{6} & $\begin{array}{l}\text { Ter conhecimento e habilidade em negociar com os clientes é um fator crítico para o } \\
\text { desempenho da minha empresa. }\end{array}$ & \\
\hline & $\begin{array}{l}\text { Habilidades Emocionais } \\
\end{array}$ & Adaptado de \\
\hline 7 & Procuro manter a autoestima mesmo em situações de grandes dificuldades. & \multirow{8}{*}{$\begin{array}{c}\text { Carland, } \\
\text { Carland e Hoy } \\
(1992), \\
\text { Fernandes et } \\
\text { al. (2007), } \\
\text { Stewart e } \\
\text { Roth (2007) }\end{array}$} \\
\hline 8 & Costumo ficar calmo mesmo em situações em que me deixam preocupado ou perturbado. & \\
\hline 9 & Tenho uma forte capacidade de superar uma crise emocional (resiliência). & \\
\hline 10 & Costumo ficar irritado quando alguma coisa não dá certo. & \\
\hline 11 & Lido bem com as incertezas (riscos, vulnerabilidades) de mercado. & \\
\hline 12 & Considero-me um gestor otimista. & \\
\hline 13 & Tenho uma forte motivação para vencer e ser um empresário bem sucedido. & \\
\hline 14 & Considero que correr riscos é algo necessário ou inerente em minha empresa. & \\
\hline $\mathbf{N}^{\mathbf{o}}$ & Mente Linear & Adaptado de \\
\hline 15 & Procuro manter minhas atividades e a empresa de forma organizada. & \multirow{6}{*}{ Brewer (1987) } \\
\hline 16 & Procuro planejar as atividades antes de realizá-las (executá-las). & \\
\hline 17 & Considero-me um bom líder na minha empresa. & \\
\hline 18 & Antes de tomar uma decisão costumo identificar as implicações de minha escolha. & \\
\hline 19 & Costumo analisar a viabilidade de um negócio antes de efetivá-lo. & \\
\hline 20 & Capacitar minha equipe de trabalho é uma das prioridades de minha gestão. & \\
\hline $\mathbf{N}^{\mathbf{o}}$ & Relacionamento & Adaptado de \\
\hline 21 & O bom relacionamento com meus clientes é um fator crítico de sucesso de minha empresa. & \multirow{9}{*}{$\begin{array}{c}\text { Gardner } \\
(1994) \mathrm{e} \\
\text { Cooper e } \\
\text { Sawaf (1997) }\end{array}$} \\
\hline 22 & $\begin{array}{l}\text { O bom relacionamento com meus colaboradores (equipe de trabalho) é um fator crítico de } \\
\text { sucesso de minha empresa. }\end{array}$ & \\
\hline 23 & $\begin{array}{l}\text { O bom relacionamento entre os meus colaboradores (equipe de trabalho) é um fator crítico } \\
\text { de sucesso de minha empresa. }\end{array}$ & \\
\hline 24 & $\begin{array}{l}\text { O bom relacionamento entre os meus fornecedores é um fator crítico de sucesso de minha } \\
\text { empresa. }\end{array}$ & \\
\hline 25 & De forma geral, consigo me relacionar bem com as pessoas? & \\
\hline 26 & $\begin{array}{l}\text { Gosto mais de trabalhar em atividadesque envolvam relacionamento com outras pessoas } \\
\text { (clientes e colaboradorses) do que em atividades técnicas e operacionais. }\end{array}$ & \\
\hline 27 & Reconheço e ouço idéias e sugestões de outras pessoas de minha equipe. & \\
\hline 28 & $\begin{array}{l}\text { Demonstro preocupação pelo cliente quando ocorre alguma falha nos produtos ou serviços } \\
\text { prestados pela empresa. }\end{array}$ & \\
\hline 29 & Preocupo-me com a melhoria de desempenho da minha empresa. & \\
\hline $\mathbf{N}^{\mathbf{0}}$ & Missão e Estratégia & Adaptado de \\
\hline 30 & Costumo traçar objetivos para a empresa para a minha equipe de trabalho. & \multirow{3}{*}{ Porter (1986) } \\
\hline 31 & $\begin{array}{l}\text { Grande parte das minhas atividades estão voltadas para construção de um futuro melhor } \\
\text { para a empresa. }\end{array}$ & \\
\hline 32 & $\begin{array}{l}\text { Frequentemente coletamos e avaliamos dados e informações sobre o mercado (por } \\
\text { exemplo, sobre clientes, fornecedores, concorrentes, taxa de câmbio, PIB (Produto Interno }\end{array}$ & \\
\hline
\end{tabular}

REAd | Porto Alegre - Edição 79 - N 3 - setembro/dezembro 2014 - p. 713-739 


\begin{tabular}{|c|c|c|}
\hline & Bruto), taxa de crescimento da indústria, etc.). & \\
\hline 33 & $\begin{array}{l}\text { Frequentemente há reuniões interdepartamentais para discutir tendências e cenários de } \\
\text { mercado. }\end{array}$ & \\
\hline 34 & $\begin{array}{l}\text { Na empresa, o pessoal é constantemente informado ou orientado para saber como atender } \\
\text { melhor o cliente. }\end{array}$ & \\
\hline 35 & Faço o planejamento das atividades da empresa com regularidade. & \\
\hline 36 & Pretendo tornar minha empresa maior (crescer) nos próximos anos. & \\
\hline $\mathbf{N}^{\mathbf{0}}$ & Criatividade e Inovação & Adaptado de \\
\hline 37 & $\begin{array}{l}\text { Nas decisões de lançamento de novos produtos ou de busca de melhorias nos produtos } \\
\text { atuais, costumo ser mais proativo do que reativo. }\end{array}$ & \multirow{8}{*}{$\begin{array}{c}\text { Deakins } \\
(1996) \mathrm{e} \\
\text { Dornelas } \\
(2005)\end{array}$} \\
\hline 38 & Considero minha empresa inovadora. & \\
\hline 39 & A iniciativa e a criatividade das pessoas são valorizadas na minha empresa. & \\
\hline 40 & $\begin{array}{l}\text { Costuma-se recompensar os colaboradores que apresentam uma idéia criativa que traga } \\
\text { alguma melhoria para a empresa. }\end{array}$ & \\
\hline 41 & Sou um agente de mudançae de melhorias na minha empresa. & \\
\hline 42 & Identifico com uma certa frequencia novas oportunidades de mercado. & \\
\hline 43 & $\begin{array}{l}\text { Nossos colaboradores são encorajados aencontrar novas maneiras de resolver problemas e } \\
\text { de explorar as oportunidades identificadas. }\end{array}$ & \\
\hline 44 & A empresa busca sistematicamente melhorias ou inovações em produtos e/ou serviços. & \\
\hline $\mathbf{N}^{\mathbf{o}}$ & Vocação & Adaptado de \\
\hline 45 & $\begin{array}{l}\text { Tenho como princípio de gestão a necessidade de ampliar minha empresa, de crescer cada } \\
\text { vez mais. }\end{array}$ & \multirow{11}{*}{$\begin{array}{c}\text { Damásio } \\
\text { (1996), Filion } \\
\text { (2001), } \\
\text { Goleman } \\
\text { (1996) e Kim } \\
\text { (1998) }\end{array}$} \\
\hline 46 & A busca pelo crescimento e melhoria constante faz parte da cultura da empresa. & \\
\hline 47 & Estar gerenciando minha empresa é motivo de orgulho e de realização para mim. & \\
\hline 48 & Encarro os problemas da empresa como um desafio e luto com coragem para superá-los. & \\
\hline 49 & Não costumo desistir diante das dificuldades. & \\
\hline 50 & Tenho alguns princípios que orientam minha atividade de gestor. & \\
\hline 51 & Não me importo em trabalhar mais de 10 horas por dia na empresa. & \\
\hline 52 & $\begin{array}{l}\text { Estar em constante evolução (pessoal e profissional) é um dos princípios que move minhas } \\
\text { ações na empresa. }\end{array}$ & \\
\hline 53 & Tenho muitos sonhos (objetivos de longo prazo) para a minha empresa. & \\
\hline 54 & A minha empresa tem um significado especial para mim. & \\
\hline 55 & Tenho orgulho e satisfação em trabalhar na minha empresa. & \\
\hline $\mathbf{N}^{\mathbf{0}}$ & Desempenho Organizacional & \multirow{10}{*}{ Pfeffer (2005) } \\
\hline 56 & Volume de vendas (faturamento, receitas). & \\
\hline 57 & Número de novos produtos (lançamentos). & \\
\hline 58 & Número total de produtos em linha. & \\
\hline 59 & Número de novos clientes. & \\
\hline 60 & Número total de clientes ativos. & \\
\hline 61 & Participação de mercado em relação à concorrência. & \\
\hline 62 & Lucro. & \\
\hline 63 & Rentabilidade. & \\
\hline 64 & Ativos da empresa. & \\
\hline
\end{tabular}

Fonte: Elaborado pelos autores com base na literatura e no estudo qualitativo-exploratório.

Para as questões de 1 a 55, que tratam das dimensões, utilizou-se uma escala do tipo Likert de sete pontos, variando de "1. Discordo Totalmente" e "7. Concordo Totalmente". Já nas questões 56 a 64, em relação ao desempenho organizacional, utilizou-se uma escala do 
As dimensões dos modelos mentais dos empreendedores e seus impactos sobre o desempenho organizacional

tipo Likert de sete pontos, representando o desempenho da empresa nos últimos três anos, variando de "1. Se baixou muito" e "7. Se aumentou muito".

A partir desta primeira versão do questionário, procedeu-se à validação de face ou de conteúdo (HAIR Jr. et al., 2009), em que o instrumento foi submetido à avaliação de dois experts da área. $\mathrm{Na}$ validação de conteúdo os especialistas analisaram o quanto os itens das escalas refletiam efetivamente o conteúdo de cada construto. Os especialistas (experts) também julgaram a facilidade de compreensão, o estilo de redação, as instruções para resposta, leiaute e outros aspectos do uso da escala. Após este refinamento do instrumento, o mesmo foi pré-testado com amostra de três empreendedores sendo que a análise dos resultados não apresentou problemas de entendimento dos respondentes.

O processamento para a análise dos dados foi feito nos softwares IBM SPSS Statistics 18, tendo-se utilizado as técnicas de Análise Fatorial Exploratória (AFE) e Análise de Regressão para testar o modelo teórico proposto. Para atender aos pressupostos para aplicação destas técnicas, foram ainda analisados: (i) os missing values, tendo-se eliminadas quatro observações com mais de $10 \%$ de não respostas; (ii) outliers univariados e multivariados, sendo que não foram identificados nenhum caso que apresentou valores padronizados superiores a $|3|$. Portanto, a amostra final compreendeu 113 casos válidos.

\section{ANÁLISE DOS RESULTADOS}

\subsection{Perfil da Amostra}

Quanto ao número de colaboradores, 16,1\% possuem de 1 a 10 funcionários; 59,8\% possuem de 11 a 50 funcionários; $19,6 \%$ possuem de 51 a 100 funcionários e 4,5\% possuem mais de 101 funcionários. Em relação ao tempo de mercado, 28,2\% das empresas fundadas entre 1956 a $1990,29,1 \%$ das empresas fundadas entre 1991 a $2000,32,7 \%$ das empresas forma fundadas entre 2001 a 2006 e 10\% foram fundadas entre 2007 a 2011 . A escolaridade dos empreendedores entrevistados indica que 4,4\% possuem nível de ensino fundamental, $34,5 \%$ possuem ensino médio, $28,3 \%$ possuem ensino superior incompleto, $19,5 \%$ possuem ensino superior completo e 13,3\% possuem pós-graduação. 
Deonir de Toni, Gustavo Mioranza, Gabriel Sperandio Milan \& Fabiano Larentis

\subsection{Validação Individual dos Construtos}

Antes de validar o modelo integrado, foi realizada a validação individual de cada um dos construtos do modelo teórico, tendo-se avaliado as condições de unidimensionalidade e de confiabilidade dos construtos.

A análise da unidimensionalidade foi feita a partir da Análise Fatorial Exploratória (AFE) com o método de componentes principais com rotação fatorial varimax, enquanto a de confiabilidade foi realizada por meio do cálculo dos coeficientes Alphas de Cronbach. A AFE possibilitou avaliar o agrupamento das variáveis e a qualidade dos fatores extraídos. Sendo que os testes de Kaiser-Meyer-Olkin (KMO) e de esfericidade de Bartlett indicaram um KMO de 0,767 com significância a $p<.000$. A comunalidade calculada para cada variável se situou acima de 0,50 , enquanto a variância explicada foi de $66,27 \%$ para as dimensões dos modelos mentais e $63,97 \%$ para o construto desempenho organizacional, resultados estes considerados adequados na área de ciências sociais (HAIR Jr. et al., 2009). Em relação à confiabilidade dos construtos, observou-se que todos os Alphas de Cronbach atingiram valores acima de 0,70, indicando ser satisfatória a confiabilidade interna dos construtos, conforme recomendado pela literatura (HAIR Jr. et al., 2009).

A Tabela 1 mostra como foram agrupados os fatores de acordo com o número das variáveis apresentadas, a variância explicada e a confiabilidade de cada um dos fatores.

Tabela 1 - Resultados da AFE

\begin{tabular}{l|c|c|c|c}
\hline Construtos ou Dimensões & Variáveis Componentes & $\begin{array}{c}\text { Variância } \\
\text { Explicada }\end{array}$ & $\begin{array}{c}\text { Alfa de } \\
\text { Cronbach }\end{array}$ & $\begin{array}{c}\text { Média do } \\
\text { Construto }\end{array}$ \\
\hline 1. Vocação & $49,50,52,48,53,54,55,55,47$ e 51 & 15,629 & 0,912 & 5,78 \\
\hline 2. Relacionamento & $25,28,27,29,24$ e 23 & 10,588 & 0,849 & 5,59 \\
\hline 3. Criatividade e Inovação & $39,40,38,42,41$ e 37 & 10,410 & 0,851 & 5,46 \\
\hline 4. Conhecimentos & $2,1,3$ e 6 & 7,689 & 0,817 & 5,68 \\
\hline 5. Habilidades Emocionais & $11,7,8$ e 9 & 7,564 & 0,798 & 5,45 \\
\hline 6. Mente Linear & $5,15,20$ e 4 & 7,413 & 0,701 & 5,84 \\
\hline 7. Missão e Estratégia & $33,34,35$ e 32 & 7,317 & 0,839 & 5,19 \\
\hline $\begin{array}{l}\text { 8. Desempenho } \\
\text { Organizacional }\end{array}$ & $56,57,61,62,63$ e 64 & 63,97 & 0,887 & 5,11 \\
\hline
\end{tabular}

Fonte: Elaborada pelos autores.

Os resultados da Análise Fatorial Exploratória (AFE) confirmaram um bom ajuste no que tange à escala proposta com suas dimensões de análise dos modelos mentais dos empreendedores. Desse modo, observou-se que a escala proposta se ajustou bem às 
As dimensões dos modelos mentais dos empreendedores e seus impactos sobre o desempenho organizacional

dimensões identificadas na revisão da literatura e constitui um primeiro estudo piloto para o aprimoramento da escala de mensuração dos modelos mentais dos empreendedores.

\subsection{Teste das Hipóteses de Pesquisa}

A partir dos resultados dos construtos provenientes da Análise Fatotial Exploratória (AFE), realizou-se, com as variáveis agrupadas, a análise de regressão linear múltipla. $\mathrm{O}$ objetivo desta análise foi identificar o quanto cada uma das dimensões (variáveis independentes) impacta no desempenho organizacional (variável dependente). A Tabela 2 apresenta os resultados desta análise.

Tabela 2 - Resultados da Análise de Regressão

\begin{tabular}{c|c|c|c|c}
\hline Modelo & R & R Quadrado & R Quadrado Ajustado & Erro Estimado \\
\hline 1 &, 525 &, 275 &, 227 &, 859 \\
\hline \multicolumn{5}{c}{ Fonte: Elaborada pelos autores. }
\end{tabular}

A partir da análise da regressão é possível verificar que o conjunto de variáveis independentes consegue explicar $27,5 \%$ da variável dependente, no caso desta pesquisa, o desempenho organizacional. Estudos de McGahan e Porter apud Besanko et al. (2006), sugerem que os efeitos do ambiente são responsáveis por cerca de $18 \%$ da variação nos lucros entre as empresas, enquanto que a posição competitiva é responsável por cerca de $32 \%$ da variação nos lucros. No Brasil, estudos realizados por Bandeira de Mello e Marcon (2004), indicam 7,9\% do desempenho é explicado pelos efeitos da indústria e 50,8\% dos efeitos da firma. A presente pesquisa identificou que $27,5 \%$ do desempenho das organizações pode ser explicado pelos modelos mentais dos empreendedores, que está dentro dos efeitos da firma. Este valor pode ser considerado satisfatório, se considerarmos que existem outros fatores, dentro dos efeitos da firma, que podem influenciar no desempenho das empresas pesquisas e que não foram testados pelo modelo. Portanto, tal achado de pesquisa consiste por si, em uma contribuição relevante para intensificar a investigação sobre o porquê algumas empresas conseguem obter um desempenho melhor que outras.

No que diz respeito à identificação de quais dimensões explicam melhor o desempenho organizacional a Tabela 3 apresenta as dimensões que possuem ou não um impacto significativo no desempenho organizacional e que confirmam cinco das sete hipóteses apresentadas no modelo teórico proposto. 
Deonir de Toni, Gustavo Mioranza, Gabriel Sperandio Milan \& Fabiano Larentis

Tabela 3 - Teste de hipóteses das dimensões

\begin{tabular}{|c|c|c|c|c|c|c|}
\hline $\mathbf{H}_{\mathbf{i}}$ & \multicolumn{2}{|c|}{ Relações Testadas } & Beta & Erro & Sig. & Resultados \\
\hline H1 & Conhecimentos & $\rightarrow$ Desempenho Organizacional & 0,207 & 0,08 & $\mathrm{p}=0,011$ & Suportada \\
\hline H2 & $\begin{array}{l}\text { Habilidade } \\
\text { Emocional }\end{array}$ & $\rightarrow$ Desempenho Organizacional & 0,120 & 0,097 & $\mathrm{p}=0,218$ & Não Suportada \\
\hline H3 & Mente Linear & $\rightarrow$ Desempenho Organizacional & $-0,055$ & 0,124 & $\mathrm{p}=0,658$ & Não Suportada \\
\hline H4 & Relacionamento & $\rightarrow$ Desempenho Organizacional & $-0,288$ & 0,116 & $\mathrm{p}=0,015$ & Não Suportada \\
\hline H5 & $\begin{array}{l}\text { Missão e } \\
\text { Estratégia }\end{array}$ & $\rightarrow$ Desempenho Organizacional & 0,199 & 0,103 & $\mathrm{p}=0,050$ & Suportada \\
\hline H6 & Criatividade & $\rightarrow$ Desempenho Organizacional & 0,301 & 0,010 & $\mathrm{p}=0,006$ & Suportada \\
\hline H7 & Vocação & $\rightarrow$ Desempenho Organizacional & 0,274 & 0,117 & $\mathrm{p}=0,021$ & Suportada \\
\hline
\end{tabular}

Fonte: Elaborada pelos autores.

O modelo teórico testado (vide Figura 1) apresentou resultados importantes quanto à análise. Nesse sentido, observa-se que a dimensão com maior impacto sobre o desempenho foi a $\mathbf{H 6}$ a Criatividade e Inovação $(\beta=0,301, \mathrm{p}=0,006)$. Isso indica que para os gestores pesquisados a necessidade de ambiente criativo com características e cultura inovadora é um diferencial competitivo e que propulsiona o desenvolvimento das organizações. O grande desafio reside em promover um ambiente de trabalho onde haja espaço para o florescimento de novas ideias e congruência entre as necessidades do indivíduo e as demandas da organização (ALENCAR, 2002).

A segunda dimensão com maior impacto sobre o desempenho organizacional está relacionada à H4, a qual se refere ao Relacionamento $(\beta=-0,288, p=0,015)$. Observa-se que esta dimensão teve um impacto significativo, porém, de efeito negativo. Portanto a hipótese não foi suportada. Neste sentido, para a amostra investigada, a manutenção de bons relacionamentos com colaboradores, fornecedores e clientes apresentou uma relação inversa em relação ao desempenho. Uma das possíveis explicações para este resultado pode ter relação com o conteúdo das variáveis que compõem o construto desempenho, cujas características não estão diretamente associadas ao relacionamento, como por exemplo níveis de satisfação e de confiança dos stakeholders. Além disso, o fato das dimensões relacionamento e desempenho não apresentarem correlação significativa entre si $(0,04, \mathrm{p}=$ $0,677)$ pode ter impactado na não confirmação desta hipótese. Ademais, há presença de indicadores com enfoque mais de curto prazo do que de longo prazo, ou seja, de natureza mais transacional que relacional (MORGAN, 2000). Mesmo assim, tal situação merece investigação em futuros estudos.

A dimensão Vocação (H7) foi a terceira mais forte na explicação do desempenho organizacional $(\beta=0,274, \mathrm{p}=0,021)$. Esta dimensão, assim como na Análise Fatorial 
As dimensões dos modelos mentais dos empreendedores e seus impactos sobre o desempenho organizacional

Exploratória (AFE) teve uma boa explicação sobre as variáveis que formam o modelo mental $(15,629$, vide Tabela 1), o que indica que a vocação para empreender manifestada pela necessidade de realização e crescimento, pela persistência, pelo trabalho e pela busca de um sonho são fatores impactantes do modelo mental dos empreendedores e que impulsionam o desempenho das organizações.

A dimensão Conhecimentos (H1) também teve um impacto significativo no desempenho organizacional $(\beta=0,207, p=0,011)$. Por conseguinte, é possível inferir que o conhecimento técnico relativo aos produtos e aos processos, o conhecimento dos concorrentes e um bom conhecimento de negociação são aspectos que, para os gestores analisados, são impactantes no desempenho de suas organizações.

No que se refere à Missão e à Estratégia das empresas (H5), observa-se que esta dimensão também teve um impacto significativo sobre o desempenho organizacional $(\beta=$ $0,199, \mathrm{p}=0,05)$. Evidencia-se, então, que para os empreendedores, a realização de reuniões para avaliar as informações sobre o mercado, a busca de informações sobre as tendências e o planejamento das atividades constituem práticas importantes para direcionar melhor o desempenho das empresas.

No que se refere às Habilidade Emocionais (H2), a hipótese não foi suportada $(\beta=0,122, p=0,218)$. Dessa forma, a autoestima, a capacidade de resiliência e de lidar com os riscos, que são habilidades emocionais, são características que os entrevistados consideram que as possuem (média 5,45 sobre 7), no entanto, não impactam sobremaneira no desempenho de suas organizações. Da mesma forma, a dimensão Mente Linear, relacionada à H3 ( $\beta=$ - 0,055, $\mathrm{p}=0,658)$ não foi suportada. Tal construto, com suas respectivas variáveis (indicadores), assim como foi comentado na Análise Fatorial Exploratória (AFE), não se agrupou de forma coerente com a revisão da literatura no conjunto de questões propostas para a dimensão tal como é apresentado no Quadro 1.

Por outro lado, tomando por base a explicação para a falta de suporte à $\mathbf{H} 2$ e à H3, as características tanto de mente linear quanto de habilidades emocionais parecem compartilhar mais significado com relacionamento que com desempenho, ou seja, com natureza mais relacional que transacional (MORGAN, 2000). De fato, a partir da análise de correlação de Pearson, identificou-se que as correlações entre relacionamento com habilidades emocionais $(0,29, \mathrm{p}<0,01)$ e com mente linear $(0,37, \mathrm{p}<0,01)$ são superiores na comparação da associação delas com o desempenho (respectivamente $0,22, \mathrm{p}=0,02$, e $0,17, \mathrm{p}=0,07$ ). Tal fato mostra que estas dimensões estão mais fortemente relacionadas com o relacionamento do que com o 
Deonir de Toni, Gustavo Mioranza, Gabriel Sperandio Milan \& Fabiano Larentis

desempenho, e que podem ser variáveis mediadoras para a geração de um melhor desempenho organizacional. Tal perspectiva poderá ser objeto de estudos futuros.

Todavia, é cedo para descartar estas duas dimensões como não influenciadoras no desempenho organizacional, uma vez que talvez, principalmente o construto Mente Linear, que necessita ser melhor definido. Tal como indicado para o Relacionamento, há necessidade de novas investigações para confirmar ou não tal hipótese.

Desta maneira, as relações hipotetizadas suportadas indicam o quanto o desempenho organizacional é dependente de aspectos de natureza complexa e multifacetada intrínsecos aos modelos mentais dos empreendedores. Ou seja, o sucesso empresarial não depende apenas do que se propõe e se desenvolve quanto à missão e à estratégia de uma organização, mas também de quanto e de que forma os conhecimentos, a criatividade e a vocação para empreender estão presentes e se desenvolvem ao longo do tempo. Assim, identifica-se que o desempenho organizacional é impactado tanto pelo ambiente externo da organização quanto pelos fatores internos aqui representados pelos modelos mentais dos empreendedores manifestados pelo comportamento inovador, pela iniciativa, pelo conhecimento e pelas competências estratégicas.

\section{CONSIDERAÇÕES FINAIS}

Uma das questões de pesquisa que instiga muitos pesquisadores, é a busca de uma resposta plausível à questão: por que algumas organizações são bem sucedidas enquanto muitas outras não? Uma das possíveis respostas a esta questão pode estar na diferença dos modelos mentais dos empreendedores, ou dirigentes, na sua inter-relação com outras dimensões de análise.

A presente pesquisa apresenta três grandes contribuições. A primeira é a proposição de um modelo teórico fundamentado a partir da revisão na literatura a propósito das dimensões da mentalidade do empreendedor sobre o desempenho de seu negócio. Este estudo tem a finalidade de dar um importante passo na ampliação das formas de se compreender melhor esta questão, evoluindo o conhecimento existente em torno do tema. A segunda contribuição é a proposição de um instrumento de coleta de dados fundamentado a partir da revisão da literatura e de seis entrevistas em profundidade com diferentes empreendedores que ao longo dos anos obtiveram diferentes níveis de desempenho organizacional.

REAd | Porto Alegre - Edição 79 - N 3 - setembro/dezembro 2014 - p. 713-739 
As dimensões dos modelos mentais dos empreendedores e seus impactos sobre o desempenho organizacional

A terceira contribuição foi a realização de um estudo empírico com 113 empresas do setor metalomecânico da cidade de Caxias do Sul (RS), em que buscou testar como as questões se ajustam às dimensões propostas. Verifica-se que muitos podem ser os fatores que impactam na diferença do desempenho entre as empresas. O estudo de De Toni e Milan (2008) identificou que mesmo empresas com situações semelhantes no que se refere a ano de fundação, tipo de segmento, características demográficas dos empreendedores ao longo dos anos se distanciam consideravelmente no que se refere ao seu desempenho.

Neste contexto, a presente pesquisa identificou que os modelos mentais como uma forma de ver o mundo, como pensamento ou imagem arraigada na mente das pessoas influenciam o comportamento das pessoas. Assim sendo, a identificação das características ou dimensões básicas dos modelos mentais dos empreendedores desponta como um tema importante de pesquisa que pode auxiliar a entender melhor a diferença no desempenho das organizações. Com este propósito, este estudo apresenta sete dimensões básicas que podem impulsionar melhor os modelos mentais dos empreendedores para um melhor desempenho de suas organizações, são elas: o conhecimento, a habilidade emocional, a mente linear, o relacionamento, a missão e a estratégia empresarial, a criatividade e vocação (a empreender).

A partir destas sete dimensões (ou construtos) fundamentadas pela revisão da literatura, realizou-se um estudo exploratório qualitativo com o propósito de compreender melhor o fenômeno estudado e auxiliar na formulação do instrumento de coleta de dados. Assim, apresentou-se um questionário com 55 questões que dá suporte ao entendimento das sete dimensões apresentadas. Dessa forma, aplicou-se um estudo com 113 empresas do setor metalomecânico na qual identifica que o instrumento proposto, a partir da análise fatorial exploratória apresenta uma aceitável variância explicada $(66,27 \%)$ e confiabilidade (alfas acima de 0,70 ). Sendo que Unidimensionalidade foi testada e o agrupamento das variáveis foi, na sua maioria, de acordo com as dimensões propostas. Exceção para a dimensão mente linear que agrupou também variáveis relacionadas a conhecimento. Tal fato merece uma ressalva no sentido da necessidade de fundamentar melhor o construto e talvez agrupá-lo com Conhecimento, uma vez que eles podem estar relacionados. Outra ressalva necessária a se fazer é que a partir dos resultados da Análise Fatorial Exploratória (AFE), foi identificado, no primeiro refinamento das questões propostas no Quadro 1, que das 55 questões (indicadores) inicialmente propostas restaram 39 delas. Como é um estudo exploratório, cuja amostra, pelo número de variáveis, pode ser considerada pequena, há necessidade de novos estudos empíricos para refinar melhor as questões apresentadas.

REAd | Porto Alegre - Edição 79 - N 3 - setembro/dezembro 2014 - p. 713-739 
Deonir de Toni, Gustavo Mioranza, Gabriel Sperandio Milan \& Fabiano Larentis

A proposição de um modelo a partir das hipóteses de pesquisa constitui também uma contribuição teórica deste trabalho. Assim, das sete hipóteses propostas quatro delas foram confirmadas, sendo que as hipóteses H2, H3 e H4, relativas às dimensões Habilidade Emocional, Mente Linear e Relacionamento não foram suportadas. Tal resultado não invalida a influência destas dimensões. Isso merece novos estudos para primeiro fundamentar melhor a dimensão mente linear e segundo testar novamente o instrumento com uma amostra maior de empreendedores. No que se refere à explicação de $27,5 \%$ das sete dimensões sobre a variável dependente, o desempenho organizacional, em um primeiro momento, parece que tal índice é baixo, no entanto, se observarmos que o desempenho organizacional sofre influência de inúmeros fatores (dimensões), tal índice pode ser considerado satisfatório, uma vez que o instrumento mede apenas os modelos mentais dos empreendedores.

Destaca-se que os modelos mentais dos empreendedores não são os únicos fatores que impactam no desempenho de suas organizações, no entanto, as maneiras como os modelos mentais se apresentam e interagem, indicam a necessidade que as organizações cada vez mais trabalhem no sentido de valorizar as pessoas que a compõem, focando nos seus recursos e em especial nos recursos humanos, ou capital intelectual. Estes recursos são os que detêm o poder de gerar competências e de transformar modelos mentais e, por consequência, interferir no desempenho das organizações. Afinal de contas, os modelos mentais afetam fortemente o que pensamos e vemos e, consequentemente, o que fazemos. $\mathrm{O}$ valor da contribuição de uma pesquisa se define, dentre outros fatores, quando a partir de um modelo inicial se consegue produzir um número expressivo de outros estudos (VOSS; TSIKRIKTSIN; FROHLICH, 2002). Dessa forma, espera-se que este estudo estimule novas pesquisas na área capazes de compreender e fundamentar melhor a importância dos modelos mentais no direcionamento estratégico e no desempenho das organizações.

\section{REFERÊNCIAS}

ALENCAR, E. S. A gerência da criatividade. São Paulo: Makron Books, 2002.

BANDEIRA-DE-MELLO, R.; MARCON, R. Unpacking firm effects: modeling political alliances in variance decomposition of firm performance in turbulent environments. In: XXVIII Encontro Nacional da Associação de Pós Graduação e Pesquisa em Administração. Anais... Curitiba: ANPAD, 2004. 
As dimensões dos modelos mentais dos empreendedores e seus impactos sobre o desempenho organizacional

BARDIN, L. Análise de conteúdo. 3. ed. Lisboa: Edições 70, 2004.

BESANKO, D.; DRANOVE, D.; SHANLEY, M.; SCHAEFER, S. A economia da estratégia. 3. ed. Porto Alegre: Bookman, 2006.

BOHNENBERGER, M. C.; SCHMIDT, S.; FREITAS, E. C. A influência da família na formação empreendedora. In: XXXI Encontro Nacional da Associação de Pós Graduação e Pesquisa em Administração. Anais... Rio de Janeiro: ANPAD, 2007.

BREWER, W. F. Schemas versus mental models in human memory. In: MORRIS, P. (ed.). Modelling cognition. Chichester: John Wiley, p 187-197, 1987.

CARLAND, J. W.; CARLAND, J. A. C.; HOY, F. S. An entrepreneurship index: an empirical validation. Frontiers of Entrepreneurship Research. Boston: Center for Entrepreneurial Studies/Babson College, 1992.

CHAPMAN, J. A.; FERFOLJA, T. Fatal flaws: the acquisition of imperfect mental models and their use in hazardous situations. Journal of Intellectual Capital, v. 2, n. 4, p. 398-409, 2001 .

CHERMACK, T. J. Mental models in decision making and implications for human resource development. Advances in Developing Human Resources, v. 5, n. 4, p. 408-422, 2003.

COOPER, R.; SAWAF, A. Inteligência emocional na empresa. Rio de Janeiro: Campus, 1997.

CORDEIRO, A. T.; MELLO, S. C. B. de. Rupturas, permanências e ressignificações na estrutura discursiva do empreendedorismo. In: XXX Encontro Nacional da Associação de Pós Graduação e Pesquisa em Administração. Anais... Salvador: ANPAD, 2006.

DAMÁSIO, A. O erro de Descartes: emoção, razão e o cérebro humano. São Paulo: Companhia das Letras, 1996. 
Deonir de Toni, Gustavo Mioranza, Gabriel Sperandio Milan \& Fabiano Larentis

DEAKINS, D. Entrepreneurship and small firms. London: McGraw-Hill, 1996.

DE TONI, D.; MILAN G. S. A relação entre os modelos mentais dos empreendedores e o desempenho organizacional: um estudo exploratório em duas empresas do setor metalmecânico. READ - Revista Eletrônica de Administração, v. 14, n. 3, p. 1-28, 2008.

DORNELAS, J. C. A., Empreendedorismo: transformando idéias em negócios. 2. ed. Rio de Janeiro: Campus, 2005.

FERNANDES, B. H. R.; HEPP, C. P. T; GIMENEZ, F. A. P.; BULGACOV, Y. Potencial empreendedor para tipos de negócios: um estudo exploratório. In: III Encontro de Estudos de Estratégia. Anais... São Paulo: ANPAD, 2007.

FERREIRA, J. M.; RAMOS, S. C.; GIMENEZ, F. A. P. Atributos individuais, organizacionais e ambientais em empreendimentos do varejo de materiais de construção civil. In: III Encontro de Estudos de Estratégia. Anais... São Paulo: ANPAD, 2007.

FILION, L. J. Empresários e proprietários - gerentes de PME. Montreal: Maclean Hunter, 2001.

FLEURY, A.; FLEURY, M. T. L. Estratégias empresariais e formação de competências: um.quebra-cabeça caleidoscópico da indústria brasileira. 3. ed. 2. reimpressão. São Paulo: Atlas, 2006.

FLICK, U. Uma introdução à pesquisa qualitativa. 2. ed. Porto Alegre: Bookman, 2004.

GARDNER, H. Mentes que mudam: a arte e a ciência de mudara as nossas idéias e a dos outros. Porto Alegre: Artmed, 2005.

GARTNER, W. Is there an elephant in entrepreneurship? Blind assumptions in theory development. Entrepreneurship Theory and Practice, v. 25, n. 4, p. 27-40, 2001. 
As dimensões dos modelos mentais dos empreendedores e seus impactos sobre o desempenho organizacional

GOLEMAN, D. Inteligência emocional: a teoria revolucionaria que redefine o que é ser inteligente. 3. ed. Rio de Janeiro: Objetiva, 1996.

GOUVEIA, T. B.; GRISCI, C. L. I. A demanda empreendedora e o trabalho imaterial na construção da subjetividade do "empreendedor". In: XXX Encontro Nacional da Associação de Pós Graduação e Pesquisa em Administração. Anais... Salvador: ANPAD, 2006.

HAIR Jr., J. F.; ANDERSON, R. E.; TATHAM, R. L.; BLACK; W. C. Análise multivariada de dados. 6. ed. Porto Alegre: Bookman, 2009.

HAMEL, G.; PRAHALAD, C. K. Competindo pelo futuro: estratégias inovadoras para obter o controle do seu setor e criar os mercados de amanhã. Rio de Janeiro: Campus, 1995.

JOHNSON-LAIRD, P. Mental models. Cambridge: Harvard University Press, 1983.

KIM, D. H. O elo entre a aprendizagem individual e a aprendizagem organizacional. In: KLEIN, D. A. (org.). A gestão estratégica do capital intelectual. Rio de Janeiro: Qualitymark, p. 61-92, 1998.

KOHLI, A. K.; JAWORSKI, B. J. Market orientation: the construct, research propositions, and managerial implications. Journal of Marketing, v. 54, n. 2, p. 1-18, 1990.

KOTLER, P.; KELLER, K. L. Administração de marketing. 14. ed. São Paulo: Pearson, 2012.

LE BOTERF, G. Desenvolvendo a competência dos profissionais. Porto Alegre: Artmed, 2003.

LEVITT, T. A imaginação de marketing. 2. ed. São Paulo: Atlas, 1990. 
Deonir de Toni, Gustavo Mioranza, Gabriel Sperandio Milan \& Fabiano Larentis

LIM, B.; KLEIN, K. Team mental models and team performance: a field study of the effects of team mental model similarity and accuracy. Journal of Organizational Behavior, v. 27, n. 4, p. 403-418, 2006.

LUMPKIN; G. T.; DESS, G. G. Clarifying the entrepreneurial orientation construct and linking it to performance. Academy Management Review, v. 21, n.1, p. 135-172, 1996.

MACHADO-DA-SILVA, C. L.; FONSECA, V. D. S.; FERNANDES, B. H. R. Cognição e institucionalização na dinâmica da mudança em organizações. In: RODRIGUES, S. B.; CALDAS, M. P. (eds.). Novas perspectivas na administração de empresas: uma coletânea luso-brasileira. São Paulo: Iglu, p. 124-150, 2000.

MALHOTRA, N. K. Pesquisa de marketing: foco na decisão. 3. ed. São Paulo: Pearson / Prentice Hall, 2011.

MILAN, G. S.; DE TONI, D.; SCHULER, M.; DORION, E. Entendendo os modelos mentais dos empreendedores e sua relação com o desempenho organizacional. In: MILAN, G. S. (org.). Administração mercadológica: teoria e pesquisas. Volume 3. Caxias do Sul: EDUCS, 2009. cap. 1, p. 13-37.

MORGAN, R. M. Relationship marketing and marketing strategy. In: SHETH, J. N.; PARVATIYAR, A. (eds.). Handbook of relationship marketing. Thousand Oaks: Sage Publications, 2000.

MÜLLER, H. Inovação orientada para mercado: um estudo das relações entre orientação para mercado, inovação e performance. Tese de Doutorado em Administração. UFRGS / Escola de Administração. Porto Alegre: UFRGS, 2005.

NARVER, J. C.; SLATER, S. F. The effect of market orientation on business profitability. Journal of Marketing, v. 54, n. 4, p. 20-35, 1990.

PAULINO, A. D.; ROSSI, S. M. M. Um estudo de caso sobre perfil empreendedor características e traços de personalidade empreendedora. In: III Encontro de Estudos sobre Empreendedorismo e Gestão de Pequenas Empresas. Anais... Brasília: UEM/UEL/UnB, 2003. 
As dimensões dos modelos mentais dos empreendedores e seus impactos sobre o desempenho organizacional

PFEFFER, J. Changing mental models: Hr's most important task. Human Resource Management, v. 44, n. 2, p. 123-128, 2005.

PORTER, M. E. Estratégia competitiva: técnicas de análise de indústrias e da concorrência. 7. ed. Rio de Janeiro: Campus, 1986.

RIBEIRO, J. L. D.; MILAN, G. S. Planejando e conduzindo entrevistas individuais. In: RIBEIRO, J. L. D.; MILAN, G. S. (eds.). Entrevistas individuais: teoria e aplicações. Porto Alegre: FEENG/UFRGS, cap. 1, p. 9-22, 2004.

SCHULER, M. Excelência humana nas comunicações organizacionais. Estudos de Jornalismo e Relações Públicas, n. 5, p. 17-30, 2005.

SCHUMPETER, J. A. Teoria do desenvolvimento econômico. São Paulo: Abril Cultural, 1982.

STEWART, W. H.; ROTH, P. A meta-analysis of achievement motivation differences between entrepreneurs and managers. Journal of Small Business Management, v. 45, n. 4, p. 401-421, 2007.

TONET, T.; TONET, C. Por que somos como somos. Caxias do Sul: Belas-Letras, 2010.

VASCONCELLOS, G. M. R. Empreendedorismo e rede de relacionamento. In: XXXI Encontro Nacional da Associação de Pós Graduação e Pesquisa em Administração. Anais... Rio de Janeiro: ANPAD, 2007.

VEIT, M. R.; GONÇALVES FILHO, C. Mensuração do perfil do potencial empreendedor e seu impacto no desempenho das pequenas empresas. In: XXXI Encontro Nacional da Associação de Pós Graduação e Pesquisa em Administração. Anais... Rio de Janeiro: ANPAD, 2007. 
Deonir de Toni, Gustavo Mioranza, Gabriel Sperandio Milan \& Fabiano Larentis

VOSS, C.; TSIKRIKTSIS, N.; FROHLICH, M. Case research in operations management. International Journal of Operations \& Production Management, v. 22, n.2, p. 195-219, 2002.

WOLCOTT, H. F. Transforming qualitative data: description, analysis, and interpretation. Thousand Oaks: Sage Publications, 1994.

ZALTMAN, G. Rethinking market research: putting people back. Journal of Marketing Research, v. 34, n. 4, p. 456-472, 1997. 